\title{
Microstructure and mechanical properties of high- manganese-containing high-speed twin-roll cast Al-Mn-Si alloy strips and their cold-rolled sheets
}

\author{
T.Ha Nguyen ${ }^{1, *}$, Ram Song ${ }^{1}$, Yohei Harada ${ }^{2}$,Shinji Muraishi ${ }^{2}$, Shinji Kumai ${ }^{2}$ \\ Shun Maruno ${ }^{3}$, Michihide Yoshino ${ }^{3}$, and Shohei Iwao $^{3}$ \\ ${ }^{1}$ Graduate student, Tokyo Institute of Technology, 2-12-1 Ookayama, Meguro-ku, Tokyo, Japan \\ ${ }^{2}$ Department of Materials Science and Engineering, Tokyo Institute of Technology, 2-12-1 Ookayama, Meguro-ku, Tokyo, Japan \\ ${ }^{3}$ Product Research and Development Dept., Mitsubishi Aluminum Co.,Ltd, 85 Hiramatsu Susono-city, Shizuoka, Japan
}

\begin{abstract}
Al-Mn based alloys with high-manganese content are expected to have improved mechanical properties due to solid solution hardening and/or dispersion hardening. However, the increase of Mn solubility of the alloy is difficult by using the conventional DC casting. In order to solve this problem, in the present study, we focused on the twin-roll casting method which is characterized by high cooling rates. Several kinds of high Mn-containing Al-Mn-Si alloy strips were fabricated by using a vertical-type high-speed twin-roll caster equipped with a pair of watercooled copper rolls. Direct temperature measurement of the liquid melt during the casting was also performed. The alloy strips of various compositions containing up to $4 \mathrm{Mn}$ and $2 \mathrm{Si}(\mathrm{wt} \%$ ) were successfully obtained. By observing the microstructure of the cross section of the strip, we found the characteristic solidified structure. The solidified structure consisted of three layers. Two solidified shells with a columnar dendrite structure grew from the roll surfaces toward the strip center. In the mid-thickness region, the band structure consisting of equiaxed dendrites and globular grains was observed between the solidified shells. Very fine primary particles were observed in the matrix near the strip surface, while, relatively coarse particles with blocky and needle-like shape were observed in the central band of the as-cast strip. The electric conductivity measurement was performed for the as-cast strips. Mn solubility in Al matrix was estimated from the obtained values. The estimated $\mathrm{Mn}$ solubility in the Al-2Mn-xSi strips was between $1.5 \sim 1.8 \mathrm{wt} \% \mathrm{Mn}$. It was over $1.43 \mathrm{wt} \% \mathrm{Mn}$ for the Al-4Mn-xSi strips. We found that the Mn solubility of the as-cast strips was considerably high. The strips were cold-rolled to the sheets and then annealed at various conditions. They were subjected to the tensile tests, and the effects of solid solution hardening and dispersion hardening are discussed.
\end{abstract}

\section{Introduction}

Al-Mn based alloys contain $\mathrm{Mn}$ as a principal alloying element, and Si as a secondary alloying element. Fe is usually included as impurities. The alloy possesses good ductility, high corrosion resistance and thermal conductivity. Thin sheets of 3003, 3004 and 3105 alloys have been used widely for architecture and packaging materials and automobile heat-exchangers [1]. In order to improve the fuel efficiency, reduction in the thickness is required for further weight reduction. Therefore, we need to increase the strength of the alloy to achieve this task. Solid solution hardening and dispersion hardening are the promising mechanisms in the alloy $[2,3]$.

The twin-roll casting (TRC) is one of the near-netshape casting technique which can produce a metal alloy sheet directly from the molten metal. TRC is classified into two types, horizontal-type and vertical-type, depending on the roll construction. The casing speed of the horizontal-type TRC is a relatively low, therefore, a limited number of commercial alloys can be used for producing the strip by this method. In addition, the alloys with a wide freezing range often suffer from some kinds of casting defects [4]. In contrast, the vertical-type high-speed TRC (HSTRC) has a much higher casting speed compared to the horizontal-type. The strip can be produced at a very high cooling rate (over $10^{3} \mathrm{C} / \mathrm{s}$ ) $[5,6]$. The high cooling rate is considered to be effective not only for grain refinement but also for increasing the super-saturation of the alloying elements which leads to solid solution hardening and dispersion hardening.

In the present study, Al-Mn-Si alloys with a high $\mathrm{Mn}$ and $\mathrm{Si}$ content were fabricated by HSTRC. The microstructural characteristics of the as-cast strips was intensively investigated. The cast strips were also coldrolled to thin sheets and then annealed. The mechanical properties of the sheets were examined. The aim of the present study is to examine the potential of the HSTRC for producing the high-strength Al-Mn-Si alloy coldrolled sheets by enhancement of the Mn supersaturation.

\section{Experimental procedure}

Al-Mn-Si-base alloys with a high amount of $\mathrm{Mn}$ and $\mathrm{Si}$ were used in this study. The nominal composition of the alloys is listed in Table 1. A fixed amount of $0.2 \mathrm{wt} \% \mathrm{Fe}$ was added into the ingot. The original ingots were fabricated by Mitsubishi Aluminum Co. Itd.

* Corresponding author: nguyenha.aa@m.titech.ac.jp 
Table 1. Chemical composition of alloys (wt $\%$ )

\begin{tabular}{|c|c|c|c|c|}
\hline Alloy & Mn & Si & Fe & Al \\
\hline A1 & 2.00 & 1.00 & 0.20 & Bal. \\
\hline A2 & 2.00 & 1.50 & 0.20 & Bal. \\
\hline A3 & 4.00 & 1.0 & 0.20 & Bal. \\
\hline A4 & 4.00 & 1.50 & 0.20 & Bal. \\
\hline A5 & 4.00 & 2.00 & 0.20 & Bal. \\
\hline
\end{tabular}

The schematic diagram of HSTRC is shown in Fig. 1. The caster is equipped with a pair of pure copper rolls with a diameter of $300 \mathrm{~mm}$ and a width of $100 \mathrm{~mm}$. No lubricant is applied on the roll surface. The roll is cooled continuously by the running water inside the rolls. The steel plate nozzle is used for obtaining the stable melt head condition which provides the hydrostatic pressure. The nozzle is covered with heat-insulating materials. One of the rolls is fixed firmly to the base, while the other roll is installed with a series of springs for controlling the initial roll separating force.

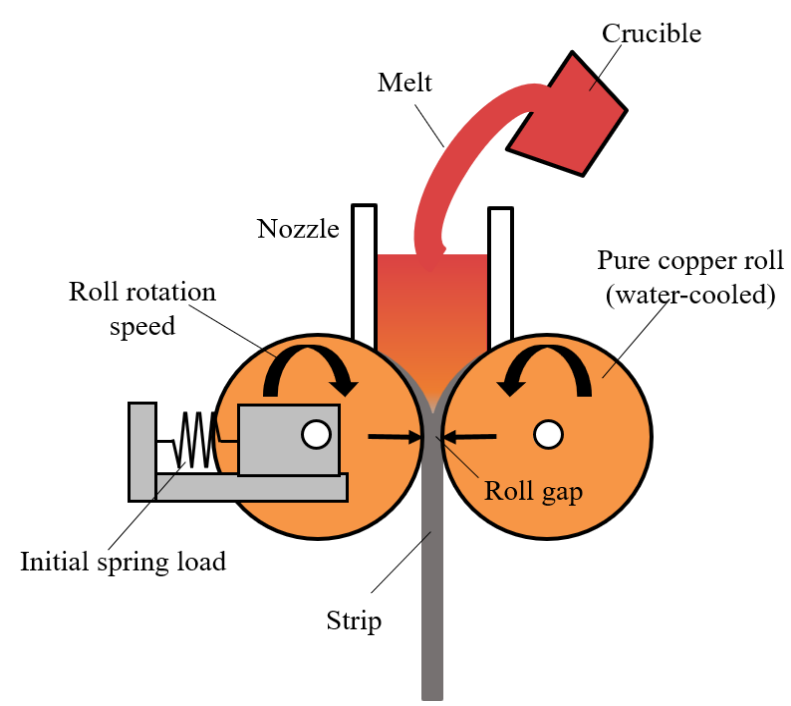

Fig. 1. Schematic diagram of Vertical Type High-Speed TwinRoll Caster

The alloy strips were fabricated by HSTRC. About $2.2 \mathrm{~kg}$ of the alloy ingot was melted in a clay-graphite crucible by using an electric resistance furnace. The melt was degassed for 20 min by introducing the Argon gas bubbles into the melt alloy before casting. The melt was solidified on both roll surfaces to form solidification shells. The solidification shells were introduced to the roll gap by the roll rotation and pressed to form the strip. The details of the casting condition are described in Table 2.

In order to estimate the supersaturated Mn content in solid solution, electrical conductivity was measured at room temperature by using SIGMA tester with $500 \mathrm{kHz}$ probe (AutoSigma 3000, GE Inspection Technology) The measurement was carried out on the normaldirection plane of the samples.
Table 2. Casting condition for each alloy

\begin{tabular}{|c|c|c|c|c|}
\hline Alloy & $\begin{array}{c}\text { Pouring } \\
\text { temperat- } \\
\text { ure }\left({ }^{\circ} \mathbf{C}\right)\end{array}$ & $\begin{array}{c}\text { Roll } \\
\text { rotation } \\
\text { speed } \\
(\mathbf{m} / \mathbf{m i n})\end{array}$ & $\begin{array}{c}\text { Initial } \\
\text { spring } \\
\text { load(kN) }\end{array}$ & $\begin{array}{c}\text { Roll } \\
\text { gap } \\
(\mathbf{m m})\end{array}$ \\
\hline A1 & 680 & 60 & 60 & 1 \\
\hline A2 & 670 & 60 & 60 & 1 \\
\hline A3 & 760 & 60 & 60 & 0.8 \\
\hline A4 & 760 & 60 & 60 & 0.8 \\
\hline A5 & 760 & 60 & 60 & 0.8 \\
\hline
\end{tabular}

The cast samples were cold-rolled to $0.1 \mathrm{~mm}$-thick sheets. The sheets were annealed at $400^{\circ} \mathrm{C}$ for $24 \mathrm{~h}$, and then subjected to the tensile tests. Fig. 2 shows the schematic diagram of the tensile test specimen. The specimen was machined from the sheet along the casting and the rolling direction.

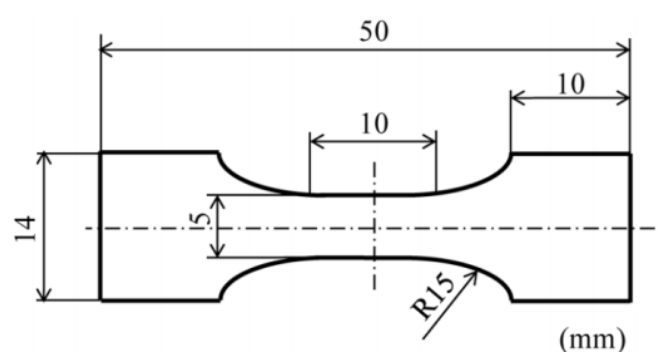

Fig. 2. Tensile test specimen (unit in $\mathrm{mm}$ )

The tensile tests were carried out by using Instrontype machine (Shimadzu AX-10kN) at room temperature. The cross-head speed was $0.5 \mathrm{~mm} / \mathrm{min}$. The change in the gage length was measure by a non-contact type laser displacement meter (Keyence LS-7500). The test was performed 3 times for each condition, and $0.2 \%$ proof stress, UTS, and elongation were obtained.

\section{Results and discussion}

\subsection{Thickness profile of as-cast strips}

Fig. 3(a) shows the thickness change of the strips, A1 and A2, along the casting direction. 2.6m-long continuous strips were successfully fabricated by HSTRC. The average thickness in the stable region was $2.3 \mathrm{~mm}$ for $\mathrm{A} 1$ and $2.2 \mathrm{~mm}$ for $\mathrm{A} 2$, respectively. Fig. 3(b) shows the thickness change of A3, A4 and A5. About $3 \mathrm{~m}$-long continuous strips were obtained. The thickness of three strips was about $1.6 \mathrm{~mm}$ on average. In total, five types of alloy were successfully cast into thin strips by using HSTRC. The microstructure was carefully examined for the part of the constant thickness, which is marked by the black boxes in Fig. 3(a) and 3(b). 
(a)

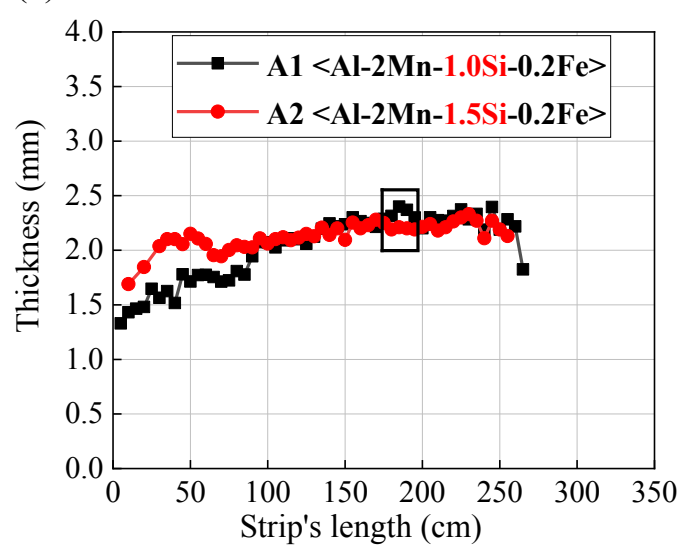

(b)

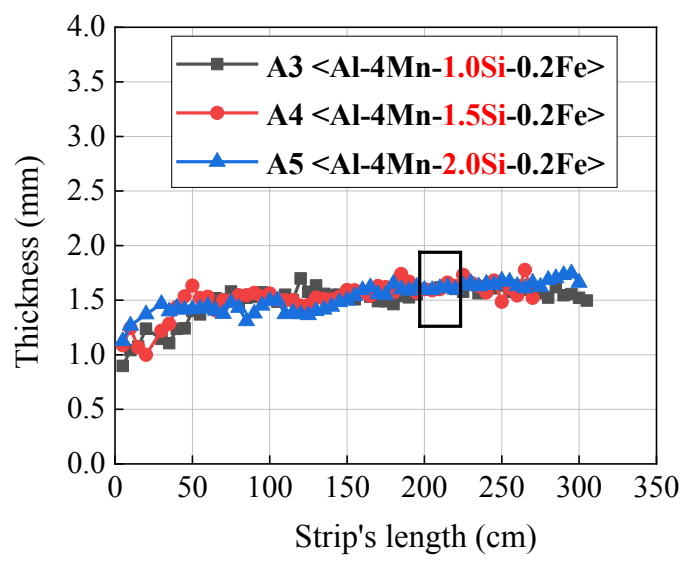

Fig. 3. Strip thickness of five Al-Mn-Si cast strips

\subsection{Grain structure of as-cast strips}

The microstructure of the cross section of as-cast strips was examined. Fig. 4 shows a representative grain structure of A1 and A3 (2 and $4 \mathrm{wt} \%$ Mn-containing) along the casting direction. As shown in Fig. 4(a), the solidified shells grown from the both roll surfaces were observed at the near-surface region. This area consists of very fine chill crystals with random orientation. Dendritic columnar grains and fine equiaxed grains were observed in the sub-surface region. In the mid-thickness region, a band area which consists of fine globular grains and equiaxed grains was observed. Fig. 4(b) shows the macrostructure of A3. This is similar to that of $\mathrm{A} 1$, in which the solidified shells are observed in both surfaces. At the near-surface region, some fine chilled crystals were observed. This layer was formed due to the very high cooling rates at the roll surfaces. After the fine chilled layer, long dendritic columnar grains were observed instead of the mixed structure of dendritic columnar and equiaxed grains in A1. The structure change is considered to be due to the fact that the casting temperature of $\mathrm{A} 3$ was much higher than that of the $\mathrm{A} 1$ (from liquidus temperature $+60^{\circ} \mathrm{C}$ and $+20^{\circ} \mathrm{C}$ for $\mathrm{A} 1$ and A3, respectively). A central band was also observed at the mid-thickness region of $\mathrm{A} 3$.
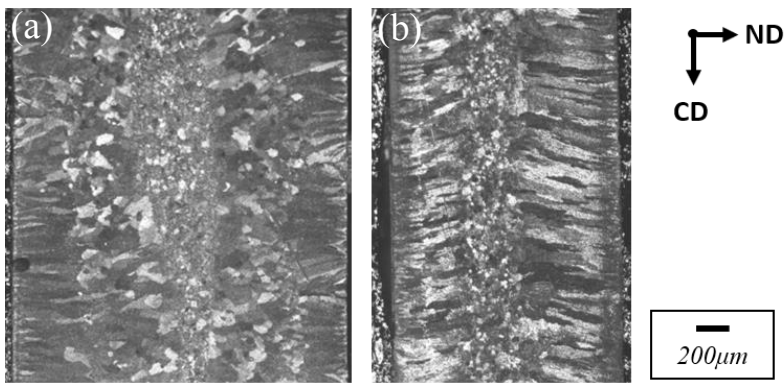

Fig. 4. Representative grain structure of the cross-section of strip. (a) A1 and (b) A3 alloy strips

In the HSTRC process, the central band structure was formed due to the entrapment of the floating crystals or the fragmented dendrite arms grown on the roll surfaces by the solidified shells. When the floating crystals are formed, they can grow to the globular grains under the convection in the nozzle. Breaking of the dendrite branches also possibly occurs at the roll gap [7]. In the A1, both of these two factors could be the origin of the globular grains in the central band. However, for the A3, due to the high casting temperature, the formation of floating crystals in the nozzle can be avoided. Therefore, the growth of fragmented dendrites in the residual liquid should be the main factor for the central band formation. Direct temperature measurement of the liquid melt during the casting was also performed. It was confirmed that the temperature of the mid-central part of the strip just after leaving from the roll nip was a little higher than the solidus temperature of the alloy.

\subsection{Microstructure of as-cast strips}

Fig. 5 shows a representative microstructure of $\mathrm{A} 1$, and A3 at the near-surface, a quarter of the thickness and the central regions. The microstructure was the typical dendritic structure, which was similar to that of the HSTRC 3003 strip [8]. At the near-surface region, cellular and equiaxed dendrite crystals were observed. A large amount of fine constituent particles was distributed inside the grains. The distribution became denser as increasing the $\mathrm{Mn}$ concentration. The structure gradually changed into a typical dendritic structure at a quarter of the thickness region. In this region, large constituent particles were frequently observed. In the mid-thickness area, globular grains were observed. Not only fine constituent particles but also a number of blocky/needlelike particles were observed. Both the amount and the size of the particles increased considerably when $\mathrm{Mn}$ was $4 \mathrm{wt} \%$. By the EPMA analysis, the large particles in the central region of A1 strip were mainly $\mathrm{Al}(\mathrm{Mn}, \mathrm{Fe}) \mathrm{Si}$. While in A3 strips, large needle-like/or platelet particles were determined as $\mathrm{Al}_{6}(\mathrm{Mn}, \mathrm{Fe})$ and $\mathrm{Al}(\mathrm{Mn}, \mathrm{Fe}) \mathrm{Si}$. 
A1
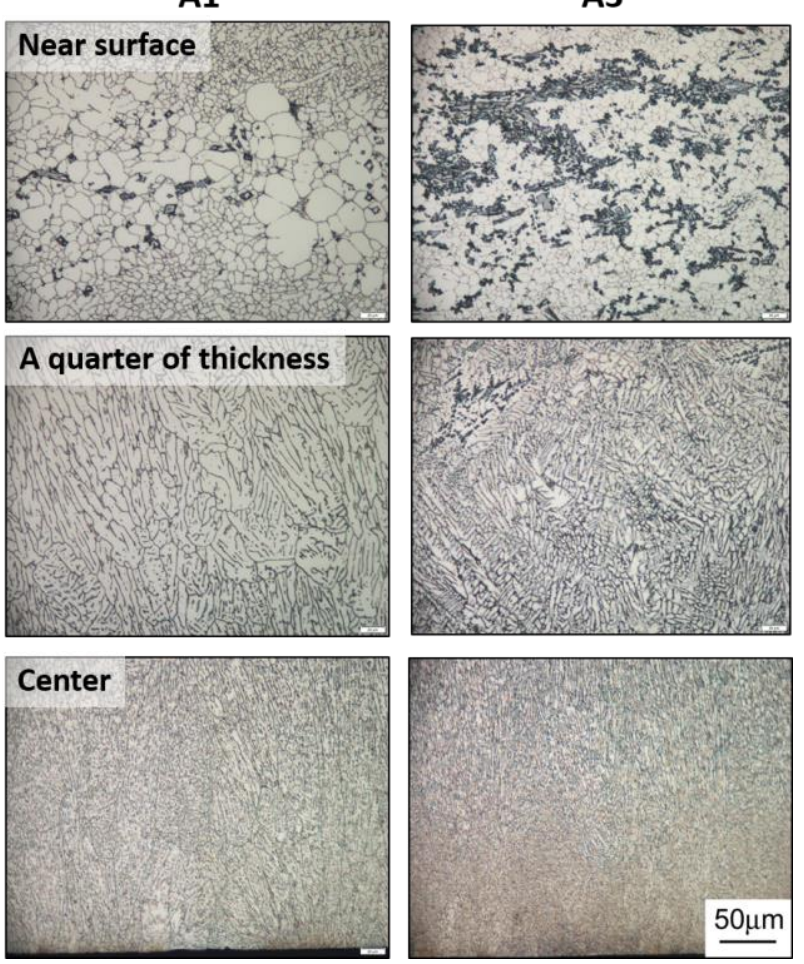

Fig. 5. Representative microstructure of the cross-section of $\mathrm{A} 1$, and $\mathrm{A} 3$ along thickness direction

\subsection{Mn solubility estimation by electrical conductivity (EC) values}

The EC of the alloy has a relationship with the concentration of an alloying elements in the solid solution. The present alloys contain $\mathrm{Mn}, \mathrm{Si}$ and a small amount of Fe. The maximum solid solubility of iron in the $\mathrm{Al}$ matrix is as small as $0.005 \mathrm{wt} \%$ [9]. It is also considered that the concentration of $\mathrm{Si}$ in solid solution has a negligible contribution to the EC change due to the very small contribution factor of 0.0068 according to the following equation from [3]:

$$
1 / \sigma=0.0267+0.032 F e_{\mathrm{SS}}+0.033 M n_{\mathrm{SS}}+0.0068 S i_{\mathrm{SS}}
$$

where $\sigma$ is the electrical conductivity, $F e_{\mathrm{SS}}, M n_{\mathrm{SS}}$, $\mathrm{Si}_{\mathrm{SS}}$ are concentration of $\mathrm{Fe}, \mathrm{Mn}$, and $\mathrm{Si}$ in the solid solution, respectively. Therefore, it is considered that the change of EC is mainly due to the content of $\mathrm{Mn}$ in the solid solution. The $\mathrm{Mn}$ concentration in the solid solution can be estimated by:

$$
\operatorname{Mn}(\mathrm{wt} \%)=\left(\rho_{\text {measure }}-\rho_{\text {pure Al }}\right) / \Delta \rho_{\text {Mn in Al alloy }}
$$

where $\rho_{\text {measure }}$ is the electrical resistivity of alloy converted by the measured electrical conductivity, $\rho_{\text {pure Al }}$ is the electrical resistivity of pure aluminum, which is $26.5 \mathrm{n} \Omega \mathrm{m}$ at room temperature, and $\Delta \rho_{\mathrm{Mn} \text { in Al alloy }}$ is the electrical resistivity contribution for $\mathrm{Mn}$ solute atom in Al matrix. The value of $\Delta \rho_{\mathrm{Mn} \text { in Al alloy }}$ is $31 \mathrm{n} \Omega \mathrm{m} \mathrm{wt}^{-1}$ at room temperature [10].
Table 3. Estimated Mn concentration in Al-Mn-Si strips

\begin{tabular}{|c|c|c|}
\hline \multirow{2}{*}{ Alloy } & \multicolumn{2}{|c|}{ Mn concentration (wt\%) } \\
\cline { 2 - 3 } & Surface & Center \\
\hline A1 & 1.87 & 1.79 \\
\hline A2 & 1.60 & 1.45 \\
\hline A3 & 2.26 & 2.05 \\
\hline A4 & 1.74 & 1.46 \\
\hline A5 & 1.46 & 1.43 \\
\hline
\end{tabular}

The estimated Mn concentration in the supersaturated solid solution is shown in Table. 3. Compared to the alloy composition for $\mathrm{Al}-2$ and $4 \mathrm{wt} \% \mathrm{Mn}$ strip, the estimated Mn contents were decreased. However, all the samples still showed high $\mathrm{Mn}$ concentration. The decrease in $\mathrm{Mn}$ concentration resulted from the formation of intermetallic phases including $\mathrm{Mn}$. The surface region showed a relatively higher $\mathrm{Mn}$ concentration than that of the central region. The cooling rate was significantly higher at the surface than the central region [6]. This might be the main factor of the difference in Mn concentration between them.

\subsection{Mechanical properties of cold-rolled sheets}

$\mathrm{A} 1, \mathrm{~A} 3$ and A5 were cold-rolled to $0.1 \mathrm{~mm}$ and annealed at $400^{\circ} \mathrm{C}$ for $24 \mathrm{~h}$. It was possible to apply a large reduction rate (about 95\%) to these strips without any homogenized steps. However, in the surface of some rolled sheets, surface defects were observed. The tensile specimens were collected from the sheet without the surface defects. Average values of the $0.2 \%$ proof stress, ultimate tensile stress (UTS) and elongation are listed in Table 4.

The sheets obtained from the HSTRC alloy strips show excellent strength. The main factor contributed to the high strength is considered to be the high supersaturated $\mathrm{Mn}$ in solid solution due to the high cooling rate of the as-cast strip. Compared to A1, A3 shows higher $0.2 \%$ proof stress and UTS due to the higher Mn concentration. However, A5 strip also had a higher strength than $\mathrm{A} 1$ in spite of the low $\mathrm{Mn}$ concentration. The Mn concentration was 1.87 and 1.46$\mathrm{wt} \%$ at the surface of A1 and A5, respectively. However, A5 has a higher $\mathrm{Si}$ concentration than that of A1. Therefore, it is considered that the increased amount of $\mathrm{Si}$ was also a factor for the improvement of strength. Compared to A1, A3 and A5 showed low elongation with a large variation. Large amount of needle-like intermetallic particles was observed in the central band of both as-cast $\mathrm{A} 3$ and $\mathrm{A} 5$-strips. $\mathrm{Al}_{6}(\mathrm{Mn}, \mathrm{Fe})$ particles are generally brittle. The particles with a high aspect ratio of needle-like/or platelet particles tend to act as stress raisers and reduce the elongation [11]. 
Table 4. Mechanical properties of cold-rolled sheets

\begin{tabular}{|c|c|c|c|}
\hline Sheet & $\begin{array}{c}\text { 0.2\% proof } \\
\text { stress (MPa) }\end{array}$ & UTS (MPa) & $\begin{array}{c}\text { Elongation } \\
(\%)\end{array}$ \\
\hline A1 & $122.3 \pm 5.5$ & $169.9 \pm 5.3$ & $11.5 \pm 1.3$ \\
\hline A3 & $162.7 \pm 17.5$ & $190.2 \pm 1.8$ & $10.7 \pm 5.9$ \\
\hline A5 & $156.4 \pm 5.7$ & $193.5 \pm 3.5$ & $9.9 \pm 8.3$ \\
\hline
\end{tabular}

We also observed the precipitated particles in the three sheets by using FE SEM. Besides the constituent particles, a large amount of fine dispersed particles was detected. In Table 4, all the sheets showed high 0.2\% proof stress, and the difference between the proof stress and UTS was relatively small (about 48, 27 and $40 \mathrm{MPa}$ in average for $\mathrm{A} 1, \mathrm{~A} 3$ and $\mathrm{A} 5$, respectively). This character is not common for the annealed solid solution strengthened alloys, but is similar to that of the agehardened alloys strengthened by the precipitates. This result suggests that the present sheets fabricated from the HSTRC strips are strengthened by the dispersed particles.

\section{Conclusion}

In total, five kinds of Al-Mn-Si strips containing up to $4 \mathrm{Mn}$ and $2 \mathrm{Si}(\mathrm{wt} \%)$ were successfully fabricated by HSTRC. Due to the high cooling rate, the substantial increase of supersaturated $\mathrm{Mn}$ concentration in solid solution was successfully obtained. The estimated Mn concentration for all samples were over $1.43 \mathrm{wt} \%$ and in particular, the highest value was about $2.2 \mathrm{wt} \%$ at the surface region of $\mathrm{Al}-4 \mathrm{wt} \% \mathrm{Mn}-1 \mathrm{wt} \% \mathrm{Si}$ alloy strip. Higher supersaturated $\mathrm{Mn}$ contributed to the high strength of cold-rolled sheets. The dispersion strengthening is considered to be the reason for the improved strength of the present sheets fabricated from the HSTRC strips.

\section{References}

1. Kissell, J. \& Pantelakis, Syros \& Haidemenopoulos, Gregory. Aluminum and Aluminum Alloys.ch9. (2004)

2. Yohei Harada, Nan Jiang, and Shinji Kumai: Mater. Trans. 60 (2019) pp. 2435-2441

3. Astrid Marie F. Muggerud, Eva Anne Mørtsell, Yanjun Li, Randi Holmestad, Mater. Sci. Eng. A, 567, (2013) pp. 21-28

4. M. Yun, S. Lokyer, J.D. Hunt, Mater. Sci. Eng. A, 280, (2000) pp.116-123

5. Min-Seok Kim, Yoshiyuki Arai, Yasuharu Hori, and Shinji Kumai: Mater. Trans. 51 (2010) pp.18541860

6. Ram Song, Yohei Harada, and Shinji Kumai, Mater. Trans. 59 (2018) pp. 110-116

7. Min-Seok Kim and Shinji Kumai: Mater. Trans. 52 (2011) pp.856-861
8. Ram Song and Shinji Kumai: Mater. Trans. 60 (2019) pp.322-329

9. A.L. Kearney: Properties of Cast Aluminum Alloys, Properties and Selection: Nonferrous Alloys and Special-Purpose Materials, vol. 2, ASM Handbook, ASM International (1990)

10. Shin-ya Komatsu, Shin-Itiro FujiKawa, J. Jpn. Inst. Light Met. 47 (1997) pp.170-181

11. J. R. Davis, Aluminum and aluminum alloys (ASM international, 1993) 